\title{
THERMODYNAMIC STUDY OF THE SOLUBILITY OF NAPROXEN IN SOME 2-PROPANOL + WATER MIXTURES
}

Fecha de recepción: 24 de junio de 2015 • Fecha de Evaluación: 11 de febrero de 2016 • Fecha de aceptación: 14 de marzo de 2016

\section{ESTUDIO TERMODINAMICO DE LA SOLUBILIDAD DEL NAPROXENO EN ALGUNAS MEZCLAS 2-PROPANOL + AGUA}

Diego Iván Caviedes Rubio, Gerson Andrés Rodríguez Rodríguez², Daniel Ricardo Delgado1*

\begin{abstract}
The equilibrium solubilities of the anti-inflammatory drug naproxen (NPX) in 2-propanol + water mixtures were determined at several temperatures from 298.15 to $313.15 \mathrm{~K}$. The Gibbs energy, enthalpy, and entropy of solution and of mixing were obtained from these solubility data. The solubility was maximal in $\varphi_{1}=0.90$ and very low in pure water at all the temperatures studied. A non-linear plot of $\Delta_{\text {soln }} H^{\circ}$ vs. $\Delta_{\text {soln }} G^{\circ}$ with negative slope from pure water up to 0.20 in volume fraction of 2-propanol and positive beyond this composition up pure 2-propanol was obtained at the mean temperature, $305.55 \mathrm{~K}$. Accordingly, the driving mechanism for NPX solubility in the water-rich mixtures was the entropy, probably due to water-structure loss around nonpolar moieties of the drug and for the 2-propanol-rich mixtures it was the enthalpy, probably due to its better solvation of the drug.
\end{abstract}

Key words: naproxen, solubility, thermodynamic of solutions, 2-propanol.

1 Programa de Ingeniería Industrial, Facultad de Ingeniería, Universidad Cooperativa de Colombia, Neiva-Huila, Calle 11 No. $1 \mathrm{G}-31 \mathrm{~B}$.

2 Grupo de Investigaciones Farmacéutico-Fisicoquímicas, Departamento de Farmacia, Facultad de Ciencias, Universidad Nacional de Colombia, AA 14490, Bogotá, Colombia.

${ }^{\star}$ Author to whom correspondence should be addressed: D.R. Delgado. E-mail: danielr.delgado@campusucc.edu.co 


\section{RESUMEN}

Se determinó la solubilidad en equilibrio del naproxeno (NPX) en mezclas de agua + 2-propanol a varias temperaturas desde 298,15 a 313,15 K. La energía de Gibbs, entalpía y la entropía de la solución fueron obtenidas a partir de los datos de solubilidad. La solubilidad máxima se obtuvo en $\varphi_{1}=0,90$ y la más baja en agua pura a todas las temperaturas estudiadas. Se presenta una relación no lineal entre $\Delta_{\text {soln }} H^{\circ}$ vs. $\Delta_{\text {soln }} G^{\circ}$ con pendiente negativa a partir del agua pura hasta 0,20 en fracción de volumétrica de 2-propanol y a partir de esta composición hasta 2-propanol puro se obtuvo una pendiente positiva a la temperatura armónica media, 305,55 K, en consecuencia, la solubilidad NPX en las mezclas ricas en agua es conducido por la entropía, probablemente debido a la pérdida de estructura-agua alrededor de grupos no polares del fármaco y para las mezclas ricas en 2-propanol quien dirige el proceso es la entalpía, probablemente debido a la mejor solvatación del fármaco.

Palabras clave: Naproxeno, solubilidad, termodinámicas de soluciones, 2-propanol.

\section{INTRODUCTION}

Solubility of drugs in co-solvent mixtures knowledge is important for pharmaceutical scientists involved in several development stages such as drug purification and design of liquid medicines (Jouyban, 2010). Although co-solvency has been employed in pharmacy for centuries it is recently that the mechanisms involved to increase or decrease drugs solubility have been approached from a physicochemical point of view (Rubino, 1988).

Naproxen (Fig. 1) is a nonsteroidal anti-inflammatory drugs (NSAIDs), with analgesic and antipyretic properties used in the treatment of rheumatoid arthritis and other rheumatic or musculoskeletal disorders, dysmenorrhea, and acute gout (Mishra et al. 2015). The other hand the 2-propanol dissolves a wide range of non-polar compounds. It also evaporates and leaves nearly zero traces, compared to other alcohol, and is relatively non-toxic, compared to alternative solvents. Thus, it is very used as a solvent in pharmaceutical industry. (Marcus, 1998).<smiles>COc1ccc2cc([C@@H](C)C(=O)O)ccc2c1</smiles>

Figure 1. Chemical structure of naproxen.

The main goal of this paper is to evaluate the solution thermodynamic of naproxen in 2-propanol + water co-solvent mixtures, based on thermodynamic definitions. Thus, this work is similar to the ones presented previously in the literature for some drugs in co-solvent mixtures (Delgado et al. 2011a; 2011b; 2012; 2013a; 2013b; Delgado y Martínez, 2013).

\section{RESULTS AND DISCUSSION}

The solubility of NPX in 2-propanol + water mixtures (Fig. 2) was taken from the literature (Mohammadzade et al. 2015). 


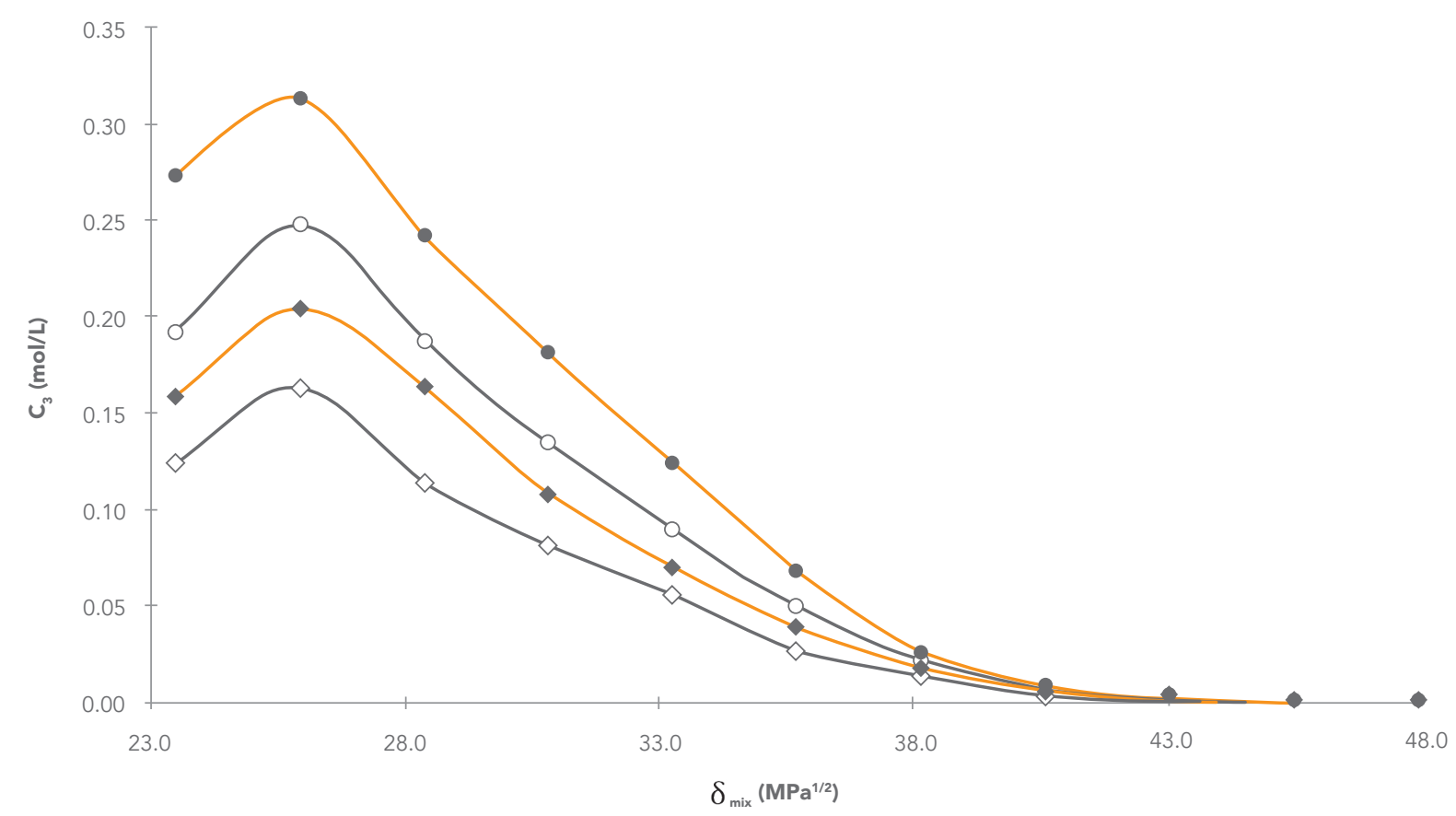

Figure 2. Experimental molar solubility of naproxen in 2-propanol + water mixtures at different temperatures; $(\Delta=298.15 \mathrm{~K} ; \quad=303.15 \mathrm{~K} ; \mathrm{O}=308.15 \mathrm{~K}$ and $\bullet=313.15$ K). Data from Mohammadzade et al. (2015).

Thermodynamic functions of solution

From these data, the thermodynamic functions are calculated solution. So the standard molar enthalpy change of solution, $\Delta_{\text {soln }} H^{\circ}$, is obtained from the slope of a $\ln x_{3}$ vs. $1 / T-1 / T_{h m}$ plot. Over the limited temperature interval ( 298.15 to $313.15 \mathrm{~K}$ ) the heat capacity change of solution may be assumed to be constant, hence $\Delta_{\text {soln }} H^{\circ}$ should be valid for the mean harmonic temperature, $T_{\text {mean }}=305.55 \mathrm{~K}$ (Krug et al. 1976a, 1976b; Jiménez et al. 2015) :

$$
\Delta_{\text {soln }} H^{\circ}=-R\left(\frac{\partial \ln C_{3}}{\partial\left(\frac{1}{T}-\frac{1}{T_{h m}}\right)}\right)_{P}
$$

The apparent standard Gibbs energy change for the solution process $\left(\Delta_{\text {soln }} G^{\circ}\right)$ considering the approach proposed by Krug et al., is calculated at $305.55 \mathrm{~K}$ by means of (Krug et al. 1976a, 1976b)
(2)

$$
\Delta_{\text {soln }} G^{\circ}=-R T \times \text { Intercept }
$$

The standard molar entropy change for the solution process, $\Delta_{\text {soln }} S^{\circ}$, at the mean harmonic temperature, $T_{\mathrm{hm}}=305.55 \mathrm{~K}$ is then

$$
\Delta_{\text {soln }} S^{\circ}=\frac{\Delta_{\text {soln }} H^{\circ}-\Delta_{\text {soln }} G^{\circ}}{T_{h m}}
$$

Table 1 presents the standard molar thermodynamic functions for dissolution of NPX (3) in all the 2-propanol (1) + water (2) solvent mixtures (Ruidiaz et al. 2010). The propagation of uncertainties in the thermodynamic quantities calculations was made according to the literature (Bevington, 1969, Taylor y Kuyatt, 1994).

The standard Gibbs free energy of solution is positive in all cases as is the enthalpy of solution; therefore the process is always endothermic. In Figure 3 show change of enthalpy versus the volume fraction of 2-propanol. The increased enthalpy between pure water up 
Table 1. Apparent thermodynamic functions relative to solution process of naproxen in 2-propanol + water cosolvent mixtures at $305.55 \mathrm{~K}$.

\begin{tabular}{ccccccc}
\hline$\varphi_{1}{ }^{b}$ & $\Delta_{\text {soln }} G^{\circ}$ & $\Delta_{\text {soln }} H^{\circ}$ & $\Delta_{\text {soln }} S^{\circ}$ & T $\Delta_{\text {soln }} S^{\circ}$ & $\zeta_{H}$ & $\zeta_{\text {TS }}$ \\
\hline 0.00 & $19.77 \pm 0.04$ & $31.2 \pm 2.3$ & $37.3 \pm 2.8$ & $11.4 \pm 0.8$ & 0.732 & 0.268 \\
\hline 0.10 & $19.55 \pm 0.03$ & $48.7 \pm 1.9$ & $95 \pm 4$ & $29.2 \pm 1.1$ & 0.626 & 0.374 \\
\hline 0.20 & $17.03 \pm 0.13$ & $68 \pm 7$ & $167 \pm 18$ & $51 \pm 5$ & 0.572 & 0.428 \\
\hline 0.30 & $13.00 \pm 0.18$ & $48 \pm 10$ & $114 \pm 23$ & $35 \pm 7$ & 0.579 & 0.421 \\
\hline 0.40 & $10.01 \pm 0.04$ & $33.8 \pm 2.3$ & $78 \pm 5$ & $23.6 \pm 1.6$ & 0.587 & 0.413 \\
\hline 0.50 & $7.97 \pm 0.05$ & $47.5 \pm 2.5$ & $129 \pm 7$ & $39.5 \pm 2.1$ & 0.546 & 0.454 \\
\hline 0.60 & $6.37 \pm 0.06$ & $41 \pm 3$ & $113 \pm 10$ & $34.4 \pm 3.0$ & 0.542 & 0.458 \\
\hline 0.70 & $5.36 \pm 0.03$ & $41.0 \pm 1.7$ & $117 \pm 5$ & $35.7 \pm 1.4$ & 0.535 & 0.465 \\
\hline 0.80 & $4.49 \pm 0.08$ & $37 \pm 4$ & $107 \pm 13$ & $33 \pm 4$ & 0.532 & 0.468 \\
\hline 0.90 & $3.776 \pm 0.019$ & $33.1 \pm 1.0$ & $96 \pm 3$ & $29.4 \pm 0.9$ & 0.530 & 0.470 \\
\hline 1.00 & $4.36 \pm 0.07$ & $40 \pm 10$ & $116 \pm 12$ & $35 \pm 3$ & 0.529 & 0.471 \\
\hline
\end{tabular}

a Data from Mohammadzade et al. (2015).

${ }^{\mathrm{b}} \varphi_{1}$ is the volume fraction of 2 -propanol in the cosolvent mixture free of solute.

to the mixture with $\varphi_{1}=0.20$, indicates that solubility is favored for entropy in these mixtures. This is due to that increase the ethanol reduces of the hydrophobic effect. The other hand, from the mixture with $\varphi_{1}=0.20$ up to the mixture with $\varphi_{1}=0.90$ the enthalpy of solution tends to decrease increase that is responsible for increasing the solubility. However in the mixture with $\varphi_{1}=0,4$ and occurs anomaly decrease of enthalpy. FinaIly between the mixture $\varphi_{1}=0.9$ and the pure 2-propanol, the enthalpy increase, possibly due to the polymerization of 2-propanol in 2.propanol-rich mixtures.

The entropy of solution is positive in all solvent mixtures and neat solvent, indicating the entropy as driving the solution process. The $\Delta_{\text {soln }} H^{\circ}$ values increase nonlinearly from pure water up to the mixture with $\varphi_{1}=0.20$ where the greatest enthalpic value is obtained and later they diminished; on the other hand, the $\Delta_{\text {soln }} S^{\circ}$ values increase nonlinearly from pure water up to the mixture with $w_{1}=0.2$ and later they this values fluctuate between 78 and $116 \mathrm{~J} \mathrm{~mol}^{-1} \mathrm{~K}^{-1}$.
The relative contributions by enthalpy $\left(\zeta_{H}\right)$ and entropy (לTs) toward the solution process, are given by equations (3) and (4) (Perlovich et al. 2004)

(3)

$$
\begin{gathered}
\zeta_{H}=\frac{\left|\Delta_{\text {soln }} H^{\circ}\right|}{\left|\Delta_{\text {soln }} H^{\circ}\right|+\left|T \Delta_{\text {soln }} S^{\circ}\right|} \\
\zeta_{T S}=\frac{\left|\Delta_{\text {soln }} S^{\circ}\right|}{\left|\Delta_{\text {soln }} H^{\circ}\right|+\left|T \Delta_{\text {soln }} S^{\circ}\right|}
\end{gathered}
$$

(4)

The main contributor to the (positive) standard molar Gibbs energy of solution of NPX, in all cases, is the (positive) enthalpy ( $\left.\zeta_{H}>0.53\right)$. The other hand the experimental of the thermodynamic functions of solutions are collected in Fig. 4. The regions where $\left(\Delta_{\mathrm{tr}} H^{\circ}>\mathrm{T} \Delta_{\mathrm{tr}} S^{\circ}>0\right)$ = sector $\mathrm{I}$; $\left(\Delta_{\mathrm{tr}} H^{\circ}<0 ; \mathrm{T}_{\mathrm{tr}} \Delta \mathrm{S}^{\circ}>0\right)$ correspond to enthalpy determined processes (Perlovich et al. 2008.), corresponding to that proposed by the equations 2 and 3

\section{Thermodynamic functions of transfer}

In order to verify the effect of co-solvent composition on the thermodynamic function driving the 
solution process, Fig. 5 collected the thermodynamic functions of transfer of NPX (3) from the more polar solvents to the less polar ones. These new functions were calculated as the differences between the thermodynamic quantities of solution obtained in the less polar mixtures and the more polar ones, by means of:

$$
\Delta_{\text {tr }} F^{o}=\Delta_{\text {soln }} F_{\text {less polar }}^{\circ}-\Delta_{\text {soln }} F_{\text {more polar }}^{\circ}
$$

Where $\Delta_{\text {soln }} F^{\circ}$ thermodynamic functions $\left(\Delta_{\text {soln }} G^{\circ}\right.$, $\Delta_{\text {soln }} H^{\circ}$ or $\Delta_{\text {soln }} S^{\circ}$ ). This procedure is the same followed previously with other studies (Holguín et al. 2012) and (Delgado et al. 2010).

The regions where $\left(\Delta_{\mathrm{tr}} H^{\circ}>\mathrm{T} \Delta_{\mathrm{tr}} S^{\circ}>0\right) \equiv$ sector I; $\left(\Delta_{\mathrm{tr}} H^{\circ}<0 ; \quad \mathrm{T}_{\mathrm{tr}} \Delta \mathrm{S}^{\circ}>0 ; \quad\left|\Delta_{\mathrm{tr}} H^{\circ}\right|>\left|\mathrm{T}_{\mathrm{tr}} \Delta \mathrm{S}^{\circ}\right|\right) \equiv$ sector IV and $\left(\Delta_{\mathrm{tr}} H^{\circ}<0 ; \quad \mathrm{T} \Delta_{\mathrm{tr}} S^{\circ}<0 ; \quad\left|\Delta_{\mathrm{tr}} H^{\circ}\right|>\left|\mathrm{T} \Delta_{\mathrm{tr}} S^{\circ}\right|\right) \equiv$ sector $\checkmark$ correspond to enthalpy determined processes. The regions of the diagram where $\left(\mathrm{T} \Delta_{\mathrm{tr}} S^{\circ}>\Delta_{\mathrm{tr}} H^{\circ}\right.$ $>0$ ) $\equiv$ sector II correspond to entropy determined processes (Perlovich et al. 2008). A schematic depiction of these relationships is given in Scheme 4.
Isoenergetic curves of the $\Delta_{\mathrm{tr}} G^{\circ}$ function are marked as dotted lines in Fig. 5.

So, the process of transfer in 2-propane-rich then it may be assumed that is the drug molecule interacts more strongly with the 2-propanol, however in all cases, the behavior is very random.

\section{Enthalpy-Entropy Compensation of NPX}

There are several reports in the literature that have demonstrated enthalpy-entropy compensation effects for the solubility of drugs in aqueous co-solvent mixtures. This analysis has been used in order to identify the mechanism of the co-solvent action. Weighted graphs of $\Delta_{\text {soln }} H^{\circ}$ as a function of $\Delta_{\text {soln }} G^{\circ}$ at the mean temperature permit such an analysis (Bustamante et al. 1998; Meloun y Ferencíková, 2012).

Fig. 6 shows that NPX (3) in the 2-propanol (1) + water (2) solvent system presents a non-linear $\Delta_{\text {soln }} H^{\circ}$ vs. $\Delta_{\text {soln }} G^{\circ}$ curve with a variable negative slope in the interval from pure water up to $\varphi_{1}=0.20$. Beyond this 2 -propanol proportion a variable positive slope is obtained

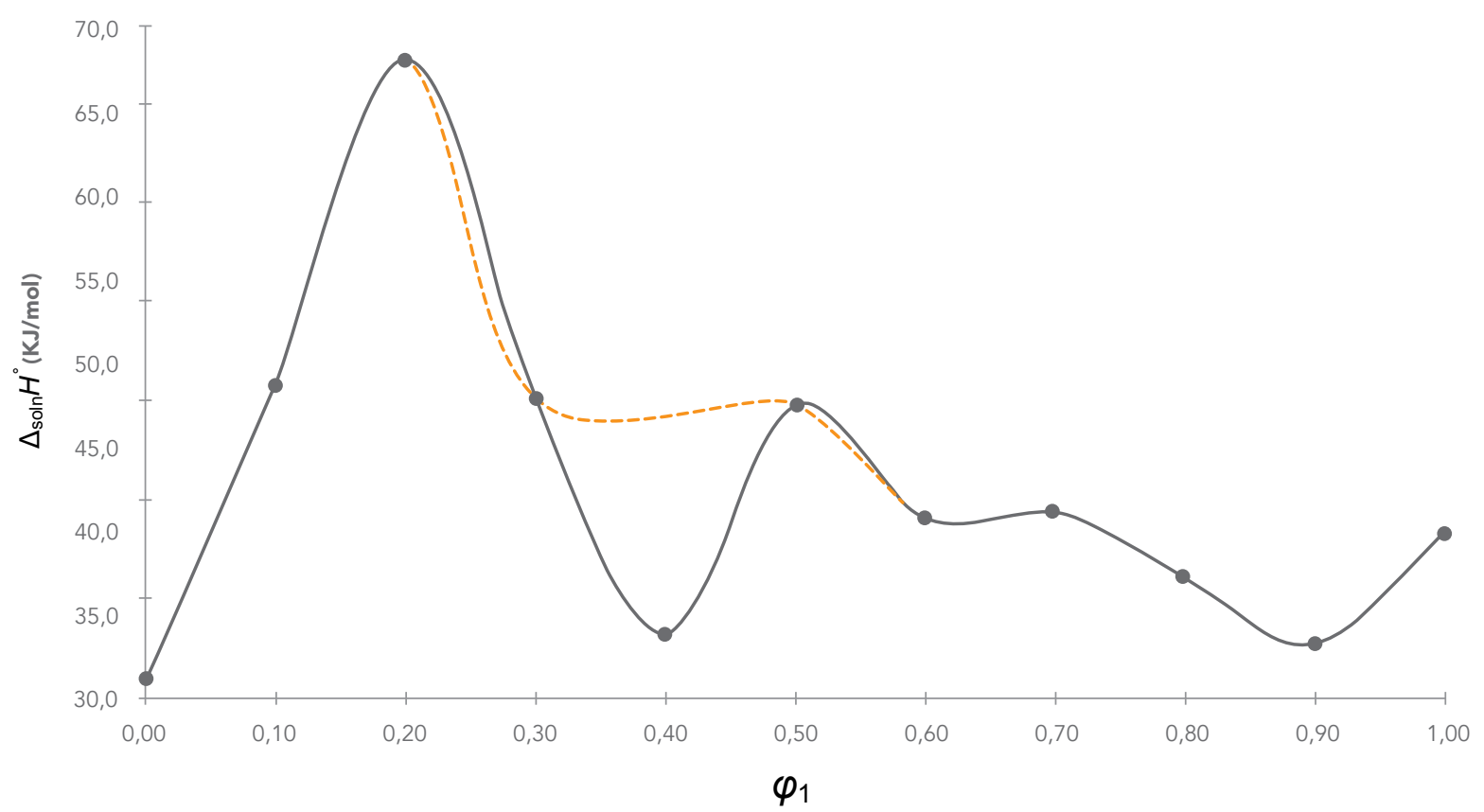

Figure 3. Enthalpy of solution of naproxen in 2-propanol (1) + water (2) mixtures at $305.55 \mathrm{~K}$. The dotted lines not consider the mixture with $\boldsymbol{\varphi}_{1}=0.4$ 


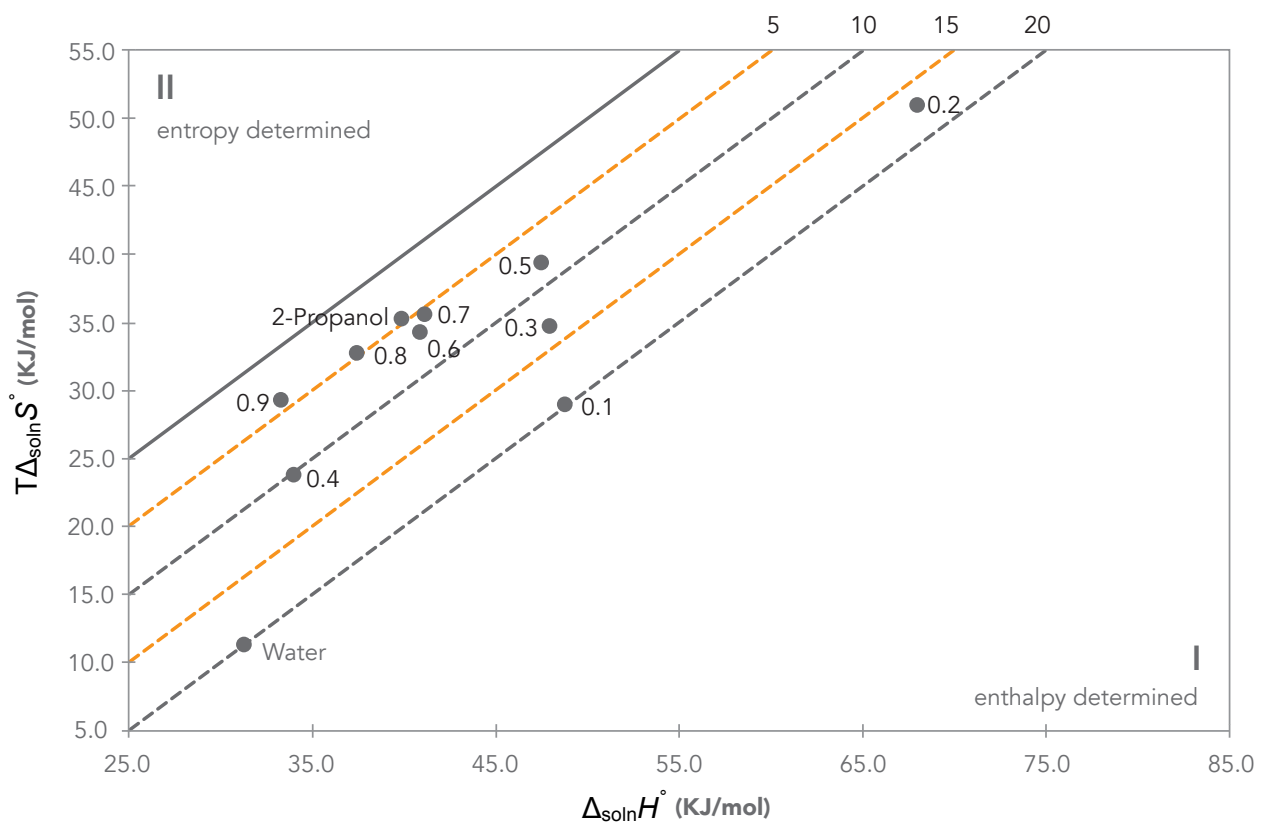

Figure 4. Relationship between the enthalpy and entropic terms of solutions functions of naproxen in 2-propanol (1) + water (2) mixtures at $305.55 \mathrm{~K}$. The isoenergetic curves of $\Delta_{\text {soln }} G^{\circ}$ function are marked by dotted lines.

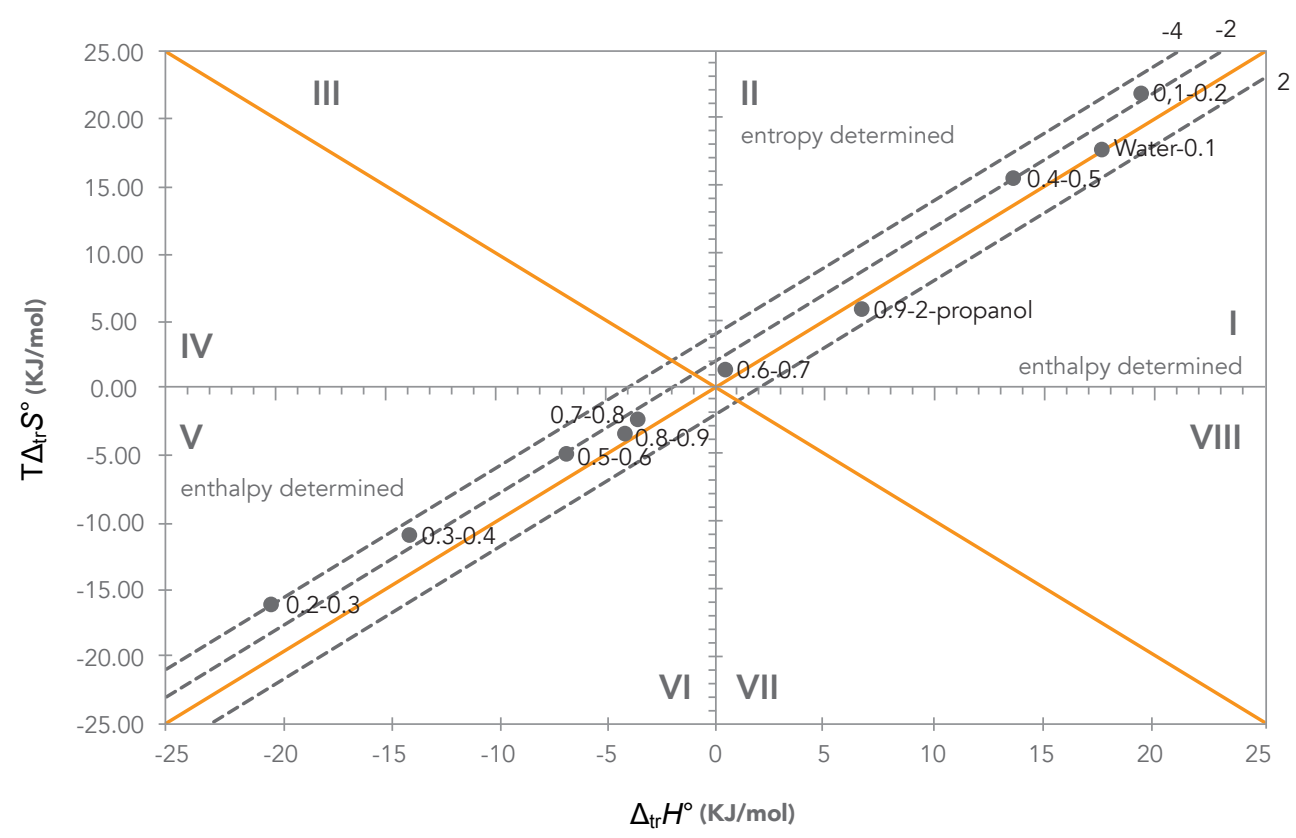

Figure 5. Relationship between the enthalpy and entropic terms of transfer functions from more polar solvents to less polar solvents at $305.55 \mathrm{~K}$. The isoenergetic curves of $\Delta_{\mathrm{tr}} \mathrm{G}^{\circ}$ function are marked by dotted lines. 


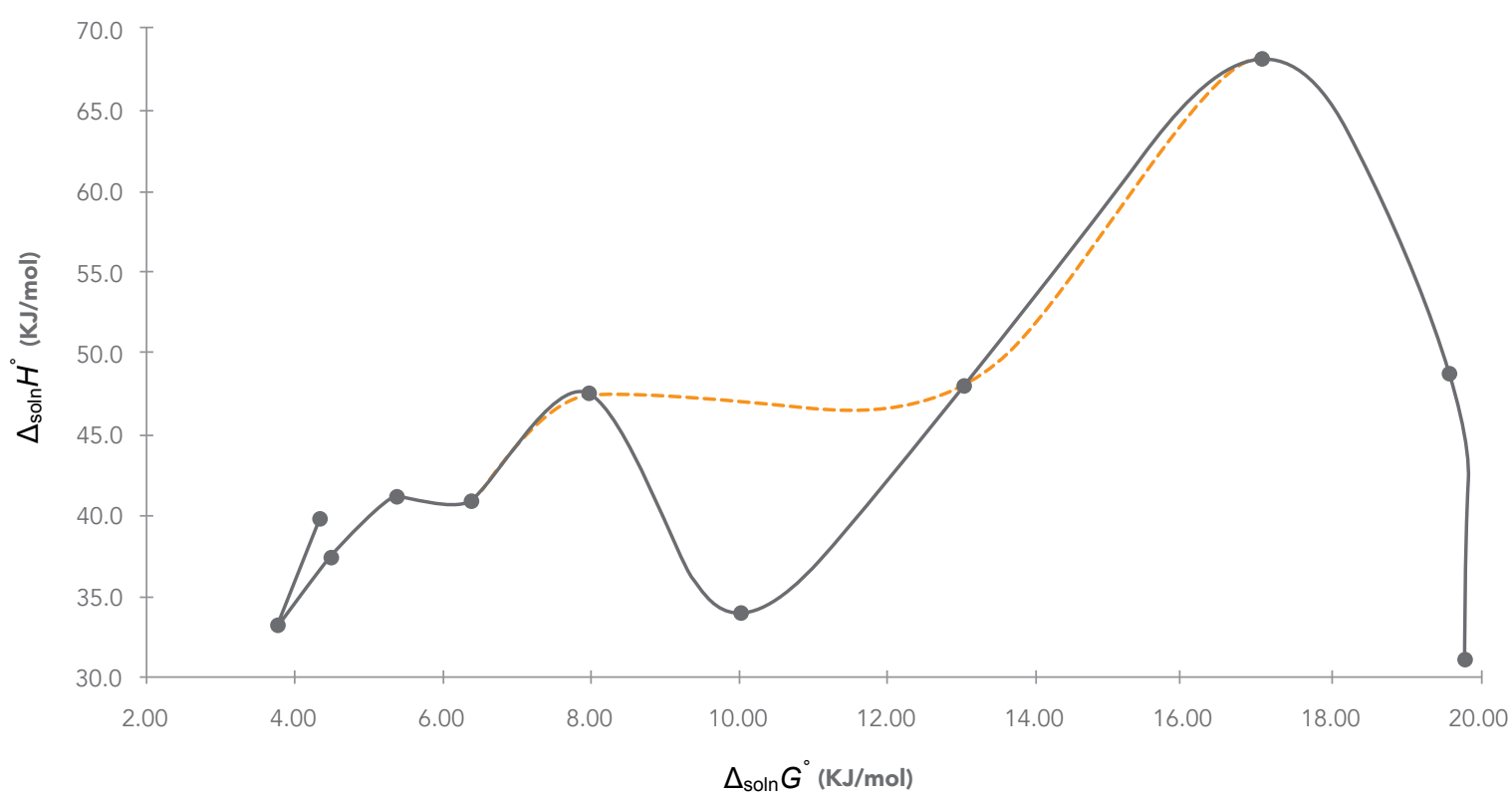

Figure 6. $\Delta_{\text {soln }} H^{\circ}$ vs. $\Delta_{\text {soln }} G^{\circ}$ enthalpy-entropy compensation plot for solubility of naproxen in 2-propanol + water cosolvent mixtures at $305.55 \mathrm{~K}$. The dotted lines not consider the mixture with $\varphi_{1}=0.4$

with exception of mixtures with 0.4 and 0.5 , a trend that is not common in these systems. Accordingly, the driving mechanism for solubility is the entropy in the former case, probably implying water-structure loosening, whereas in the latter case the driving mechanism is the enthalpy, probably due to better solvation of the drug by 2-propanol molecules.

\section{CONCLUSIONS}

From all topics discussed here it can be concluded that the solution process of NPX (3) in 2-propanol (1) + water (2) mixtures depends strongly on the solvent composition. Hydrogen bonding of the hydroxyl group of NPX to the more basic solvent component, 2-propanol, causes increased solubility the drug in the 2-propanol-rich mixtures. Non-linear enthalpy-entropy compensation was found for this drug in this solvent system. In this context, entropy-driving was found for the solution processes in compositions from pure water to the mixture having 0.20 volume fraction of 2-propanol, whereas, for mixtures beyond this propylene glycol proportion, enthalpy-driving was found. Ultimately, it can be said that the data presented in this report amplify the physicochemical information about anti-inflammatory drugs in aqueous-co-solvent solutions.

\section{REFERENCES}

1. Bevington P. 1969. Data Reduction and Error Analysis for the Physical Sciences. McGraw-Hill Book. New York, 103p.

2. Bustamante $P$, Romero $S$, Peña A, Escalera B y Reillo A. 1998. Enthalpy-entropy compensation for the solubility of drugs in solvent mixtures: paracetamol, acetanilide, and nalidixic acid in dioxane-water. Journal of Pharmaceutical Sciences. 87:1590-1596.

3. Delgado DR y Martinez F. 2013. Solution thermodynamics of sulfadiazine in ethanol + water mixtures. Journal of Molecular Liquids, 187: 99-105.

4. Delgado DR, Holguín AR, Almanza OA, Martínez F y Marcus Y. 2011b. Solubility and preferential 
solvation of meloxicam in ethanol + water mixtures. Fluid Phase Equilibria, 305: 88-95.

5. Delgado DR, Rodríguez GA y Martínez F. 2013a. Thermodynamic study of the solubility of sulfapyridine in some ethanol + water mixtures. Journal of Molecular Liquids, 177: 156-161.

6. Delgado DR, Rodríguez GA, Holguín AR, Martínez F y Jouyban A. 2013b. Solubility of sulfapyridine in propylene glycol + water mixtures and correlation with the Jouyban-Acree model. Fluid Phase Equilibria, 341: 86-95.

7. Delgado DR, Romdhani A y Martínez F. 2012. Solubility of sulfamethizole in some propylene glycol + water mixtures at several temperatures. Fluid Phase Equilibria, 322-323: 113-119.

8. Delgado DR, Romdhani A. y Martínez F. 2011a. Thermodynamics of sulfanilamide solubility in propylene glycol + water mixtures. Latin American Journal of Pharmacy 30: 2024-2030.

9. Delgado DR, Ruidiaz MA, Gómez SM, Gantiva M y Martínez F. 2010. Thermodynamic study of the solubility of sodium naproxen in some ethanol + water mixtures. Química Nova, 33: 1923-1927.

10. Holguín AR, Delgado DR y Martínez F. 2012. Thermodynamic study of the solubility of triclocarban in ethanol + propylene glycol mixtures. Química Nova, 35: 280-285.

11. Jiménez DM, Cardenas ZJ, Delgado DR, Peña MA y Matínez F. 2015. Solubility temperature dependence and preferential solvation of sulfadiazine in 1,4-dioxane + water co-solvent mixtures. Fluid Phase Equilibria, 397: 26-36

12. Jouyban A. 2010. Handbook of Solubility Data for Pharmaceuticals, CRC Press, Boca Raton, $\mathrm{FL}, 405 \mathrm{p}$.

13. Krug RR, Hunter WG y Grieger R.A. 1976a. Enthalpy-entropy compensation. 1. Some fundamental statistical problems associated with the analysis of van't Hoff and Arrhenius data. The Journal of Physical Chemistry, 80: 2335-2341.

14. Krug RR, Hunter WG y Grieger RA. 1976a. Enthalpy-entropy compensation. 2. Separation of the chemical from the statistical effect. The Journal of Physical Chemistry, 80: 2341-2351

15. Marcus Y. 1998. The Properties of Solvents, John Wiley \& Sons, Chichester, 103p.

16. Meloun M. y Ferencíková Z. 2012. Enthalpyentropy compensation for some drugs dissociation in aqueous solutions. Fluid Phase Equilibria, 328: 31-41

17. Mishra B. Sahoo J. y Kumar P. 2015. Formulation and process optimization of naproxen nanosuspensions stabilized by hydroxy propyl methyl cellulose. Carbohydrate Polymers, 127: 300-308.

18. Mohammadzade M, Barzegar-Jalali M y Jouyban A. 2015. Solubility of naproxen in 2-propanol + water mixtures at various temperatures. Journal of Molecular Liquids, 206: 110-113.

19. Perlovich GL, Kurkov SV, Kinchin AN y BauerBrandl A. 2004. Thermodynamics of solutions III: Comparison of the solvation of (+)-naproxen with other NSAIDs. European Journal of Pharmaceutics and Biopharmaceutics, 57: 411-420.

20. Perlovich GL, Strakhova NN, Kazachenko VP, Volkova TV, Tkachev W, Schaper, KJ y Raevsky OA. 2008. Sulfonamides as a subject to study molecular interactions in crystals and solutions: Sublimation, solubility, solvation, distribution and crystal structure. International Journal of Pharmaceutics, 349: 300-312.

21. Rubino JT. 1988. Cosolvents and cosolvency. 375p. In: J. Swarbrick, J.C. Boylan, (Eds) Encyclopedia of Pharmaceutical Technology. New York, 1048p

22. Ruidiaz MA, Delgado DR, Martínez R. y Marcus Y. 2010. Solubility and preferential solvation of indomethacin in 1,4-dioxane + water solvent mixtures. Fluid Phase Equilibria, 299: 259-265.

23. Taylor BN y Kuyatt CE. 1994. Guidelines for evaluating and expressing the uncertainty of nist measurement results. NIST Technical Note 12971994 Edition, United States Departament of Comerce Technology Administration. Washington D.C, 35p. 